\section{Injectable thermosensitive gels for the localized and controlled delivery of biomolecules in tissue engineering/regenerative medicine}

\author{
Monica Boffito, 1,2 \\ Arianna Grivet Brancot, 1 \\ Ornella Lima, ${ }^{2}$ Simona Bronco, ${ }^{1}$ \\ Susanna Sartori,2 Gianluca Ciardelli1,2 \\ 1Institute for Chemical-Physical \\ Processes, National Research Council \\ (CNR-IPCF), Pisa; 2Department of \\ Mechanical and Aerospace Engineering, \\ Politecnico di Torino, Turin, Italy
}

\begin{abstract}
The characteristic poor stability and high fluid permeability of Poloxamer ${ }^{\circledR}$ based gels have severely limited their biomedical application. In this work, Poloxamer 407 was used as building block to synthesize a poly(ether urethane) (PEU), which aqueous solutions formed gels with improved stability and mechanics compared to Poloxamer itself. PEU chains formed micelles in aqueous solution (diameter $\sim 40$ $\mathrm{nm}$ at $25^{\circ} \mathrm{C}$ ) and systems with PEU content higher than $5 \pm 1 \% \mathrm{w} / \mathrm{v}$ underwent a temperature-driven gelation. Gel properties were tuned acting on PEU concentration in the starting solutions, with compositions within the range $8-18 \% \mathrm{w} / \mathrm{v}$ showing high potential for biomedical applications (gelation at $37^{\circ} \mathrm{C}$ within $3-10$ minutes, residence time from few days to many weeks, injectability). Model proteins (bovine serum albumin, horseradish peroxidase) were encapsulated in mild conditions and their release was modulated by gel composition (on day 3, approx. 85,65 and $55 \%$ of encapsulated payload released from gels with 8, 15 and $18 \% \mathrm{w} / \mathrm{v}$ concentration). Released peroxidase retained approx. $30-40 \%$ of its activity up to 2 days, a key aspect for biomolecules in the drug delivery field.
\end{abstract}

\section{Introduction}

The potential biomedical application of hydrogels has been widely explored since the 1960s. Although the literature reports several definitions of the term hydrogel, ${ }^{1-3}$ they are currently defined as multi-component systems composed by a three-dimensional network of polymeric chains with spaces between macromolecules filled by water. ${ }^{4}$ These networks are characterized by the ability to swell and de-swell in aqueous environments, while keeping their shape; additionally, the amount of water absorbed also influences many properties, such as mechanical and surface properties, biocompatibility and permeability. ${ }^{5}$ Thanks to their properties, hydrogels have been frequently employed for regenerative medicine applications, especially as drug release systems in different fields, such as cancer, ${ }^{6}$ cardiovascular disease treatment, ${ }^{7}$ and skin wound dressings. ${ }^{8}$ The suitability of hydrogels in these applications is due to their ability to overcome some of the limitations of traditional drug administration routes: hydrogels release their payload with a controlled and sustained kinetics, while stabilizing and protecting the encapsulated molecule. ${ }^{9}$ Moreover, hydrogels are usually injected via non-invasive procedures, thus limiting the size of the surgical incisions needed to apply them (hydrogels are often directly injected in loco) and reducing wound healing time, pain and risk of side effects (e.g., infection).

Thermo-sensitive sol-gel systems have received particular interest in the biomedical area. The trigger point underpinning the formation of these systems is the sol-to-gel transition, which is solely induced by temperature, with no potentially toxic crosslinkers, catalysts or organic solvents required. Thermo-sensitive hydrogels can be characterized either by an upper critical gelation temperature (UCGT) or a lower critical gelation temperature (LCGT): gel formation is obtained by decreasing temperature below UCGT and increasing temperature above LCGT, respectively. In particular, LCGT hydrogels show high promise in the biomedical field, since they can be tailored as injectable systems that undergo gelation in situ after injection in physiological conditions. Other advantages include the possibility to encapsulate biomolecules at low temperature by dispersion when the system is in the sol phase and the ability of the injected systems to easily fill any defect or cavity before complete gelation. ${ }^{10}$

Poly(ethylene oxide)/poly(propylene oxide)/poly(ethylene oxide) (PEO-PPOPEO) triblock copolymers (trademark Pluronics ${ }^{\circledR}$, Poloxamers ${ }^{\circledR}$, Kolliphor ${ }^{\circledR}$ ) have been used in many literature studies to design thermo-sensitive hydrogels, especially as drug and cell carriers. ${ }^{11,12}$ Hydrogels formed by Poloxamers, however, are affected by low viscosity and mechanical strength, high permeability and a limited residence time in aqueous media, which significantly restrict the field of application of these systems. A possible solution to overtake this drawback consists in increasing
Correspondence: Gianluca Ciardelli, Department of Mechanical and Aerospace Engineering, Politecnico di Torino, Corso Duca degli Abruzzi 24, 10129 Turin, Italy. Tel.: +39.011.0906919.

E-mail: gianluca.ciardelli@polito.it

Key words: Thermosensitive gels; Payload release; Amphiphilic poly(urethane); Model proteins.

Contributions: $\mathrm{MB}, \mathrm{AGB}$, data collecting and analyzing, manuscript writing; OL, data collecting and analyzing; MB, SS, GC, manuscript reviewing and supervision; GC, project administration and funding acquisition.

Conflict of interest: the authors declare no potential conflict of interest.

Funding: the work was supported by the project PREVISION Prognostic evaluation of the use of three-dimensional bioactive scaffolds and injectable gels for the treatment of chronic lesions of the skin by means of new biomedical imaging technologies financed by Fondazione Pisa (Italy).

Conference presentation: part of this paper was presented at the National Congress of the Società Italiana di Biomateriali - SIB, 2018 June 6-8, Rende (CS), Italy.

Received for publication: 26 March 2019

Revision received: 30 April 2019.

Accepted for publication: 15 May 2019.

This work is licensed under a Creative Commons Attribution NonCommercial 4.0 License (CC BY-NC 4.0).

(C) Copyright: the Author(s), 2019

Licensee PAGEPress, Italy

Biomedical Science and Engineering 2019; 3:67 doi:10.4081/bse.2019.67

Poloxamer molecular weight by using it as repeating unit in the design of multiblock copolymers. For instance, several literature studies focused on the reaction of Poloxamers with diisocyanates, ${ }^{13-15}$ leading to the formation of poly(ether urethane)s (PEUs), which show a high chemical versatility that results in the possibility to finely tune their properties, thus making them suitable to many different applications.

In this work, an amphiphilic PEU has been synthesized starting from Poloxamer ${ }^{\circledR}$ 407, an aliphatic diisocyanate and an amino acid-derived diamine, and the potential of its aqueous solutions as gelling systems has been qualitatively and quantitatively proved by tube inverting and rheological tests. Stability in aqueous environment and injectability have been also investigated. 
Then, two model proteins have been encapsulated in the PEU gels and both the effects of these molecules on gel properties and their release kinetics have been thoroughly assessed. In detail, bovine serum albumin (BSA) and horseradish peroxidase (HRP) were selected as model proteins based on previous literature, 16 their low cost and easy quantification through commercially available colorimetric assays. Additionally, the activity and stability of the released HRP enzyme could be easily and quickly evaluated through colorimetric quantification of oxidized 3,3',5,5'-Tetramethylbenzidine (TMB) substrate. Model proteins have been loaded in hydrogels of selected compositions at an ideal concentration of $1 \mathrm{mg} / \mathrm{mL}$, taking into account that the concentration growth factors require to exert their activity is usually in the order of tens-hundreds $\mathrm{ng} / \mathrm{mL} \cdot{ }^{17,18}$ Moreover, loading of BSA or HRP at a fixed concentration has allowed a fine and thorough comparison among formulations differing only for one parameter, i.e., the polymer content.

\section{Materials and Methods}

\section{Materials}

Poloxamer 407 (P407, M 12600 Da, PEO content $70 \%$, Sigma Aldrich, Italy) was anhydrified at approx. 200 mbar at $100^{\circ} \mathrm{C}$ for 8 hours and then equilibrated at $40^{\circ} \mathrm{C}$ to be used as macrodiol during PEU synthesis. L-Lysine ethyl ester dihydrochloride (Sigma Aldrich, Italy) was stored at room temperature (RT) under reduced pressure until use, while 1,6-hexamethylene diisocyanate (HDI, Sigma Aldrich, Italy) was distilled under vacuum to remove water and stabilizers. 1,2-dichloroethane (DCE) was anhydrified in inert atmosphere over molecular sieves (previously activated at $120^{\circ} \mathrm{C}, 4 \AA$, Sigma Aldrich, Italy) overnight. Triethylammine (TEA, Sigma Aldrich, Italy) and the catalyst dibutiltin dilaurate (DBTDL, Sigma Aldrich, Italy) were used as received. All solvents were acquired from CarloErba, Italy in their analytical grade. BSA, HRP and all reagents for colorimetric assays (bicinchoninic acid - BCA - assay, TMB substrate solution) were purchased from Sigma Aldrich and used as received.

\section{Poly(ether urethane) synthesis and nomenclature}

The PEU used in the present work as hydrogel-forming material was synthesized according to an optimized protocol. ${ }^{19} \mathrm{~A}$
P407 solution in anhydrous DCE (20\% w/v) was first heated at $80^{\circ} \mathrm{C}$. Then HDI and DBTDL were added (HDI:P407=2:1 molar ratio, DBTDL at $0.1 \% \mathrm{w} / \mathrm{w}$ concentration with respect to $\mathrm{P} 407$ ) and the pre-polymerization step lasted 150 minutes. After cooling down the reaction mixture at $60^{\circ} \mathrm{C}, \mathrm{L}$ Lysine ethyl ester (LYS) was added (LYS:P407=1:1 molar ratio) upon solubilization in anhydrous DCE at $3 \% \mathrm{w} / \mathrm{v}$ concentration in the presence of TEA (TEA:LYS=3:1 molar ratio) to induce neutralization. The chain extending reaction lasted 90 minutes. The synthesized PEU was precipitated in petroleum ether (petroleum ether: $\mathrm{DCE}=4: 1$ volume ratio) and the polymer was further purified by precipitating its solution prepared in DCE in a diethyl ether/methanol mixture $(98: 2 \mathrm{v} / \mathrm{v})$ at $5: 1$ volume ratio with respect to DCE. Centrifugation at $6000 \mathrm{rpm}$ and $0^{\circ} \mathrm{C}$ for 20 minutes was performed to collect the PEU, which was finally dried under the fume hood overnight and stored under $\mathrm{N}_{2}$ at $4^{\circ} \mathrm{C}$. Hereafter, PEU will be identified with the acronym KHP407, where K, H and P407 identify L-Lysine ethyl ester, HDI and Poloxamer 407, respectively.

\section{Chemical characterization of KHP407}

KHP407 successful synthesis was proved by Attenuated Total Reflectance Fourier Transformed Infrared (ATR-FTIR) spectroscopy and Size Exclusion Chromatography (SEC).

ATR-FTIR spectra were registered by a Perkin-Elmer Spectrum 100 instrument using an ATR accessory (UATR KRS5) with diamond crystal, according to Boffito et al. $19 \mathrm{P} 407$ and KHP407 spectra were obtained between 4000 and $600 \mathrm{~cm}^{-1}$, mediating 32 scans with a resolution of $4 \mathrm{~cm}^{-1}$.

SEC analysis were performed with an Agilent Technologies 1200 Series, USA instrument carrying a Refractive Index Detector (RID) and two columns (Waters Styragel HR1 and HR4) equilibrated at $55^{\circ} \mathrm{C}$. N,N dimethylformamide (HPLC grade, CarloErba, Italy) added with $\mathrm{LiBr}$ $(0.1 \% \mathrm{w} / \mathrm{v}$, Sigma Aldrich, Italy) was used as mobile phase at $0.5 \mathrm{~mL} / \mathrm{min} .2 \mathrm{mg} / \mathrm{mL}$ concentrated PEU samples were prepared and filtered before analysis. Molecular Weight (Number Average Molecular Weight $-M_{n}-$ Weight Average Molecular Weight, $\mathrm{M}_{\mathrm{w}}$ ) and Molecular Weight Distribution $\left(D=M_{w} / M_{n}\right)$ were estimated using a calibration curve based on PEO standards (Peak Molecular Weight $\left(\mathrm{M}_{\mathrm{p}}\right)$ within the range 982-205500 Da) as reference.

\section{Characterization of KHP407 aggre- gation in aqueous medium}

\section{Dynamic Light Scattering analysis}

P407 and KHP407 solutions (0.5 and $1 \% \mathrm{w} / \mathrm{v}$ concentration) were prepared in Phosphate Buffered Saline (PBS, pH 7.4) and analyzed with a Zetasizer Nano S90 (Malvern Instruments, Worcestershire, UK) Dynamic Light Scattering (DLS) at 25, 30, 37 and $45^{\circ} \mathrm{C}$ (10 minutes equilibration at each tested temperature before analysis) according to Boffito et al. ${ }^{19}$ In each analyzed condition, three measurements were taken and results are reported as mean \pm standard deviation.

\section{Evaluation of the Critical Micellization Temperature}

Critical Micellization Temperature (CMT) of P407- and KHP407-based solutions with concentration within the range $0.1-6 \% \mathrm{w} / \mathrm{v}$ was estimated using the fluorescent dye 1,6-diphenyl-1,3,5-hexatriene (DPH, Sigma-Aldrich, Italy) as marker of micellization, according to the protocol by Alexandridis et al. ${ }^{20}$ A DPH solution in $\mathrm{MeOH}(0.4 \mathrm{mM})$ was added to polymer aqueous solutions, previously prepared in PBS, reaching a final DPH concentration of $92 \mathrm{ng} / \mathrm{mL}$. Samples were then cooled down at $4^{\circ} \mathrm{C}$ in the dark for 90 minutes and underwent a temperature increase from 5 to $35^{\circ} \mathrm{C}$ at a rate of $1^{\circ} \mathrm{C} / \mathrm{step}$, each step consisting in sample equilibration for 5 minutes followed by UV-Vis spectrum acquisition (Perkin Elmer Lambda 25 UV/VIS spectrometer Waltham, MA, USA) within the range 330$400 \mathrm{~nm}$ (resolution $1 \mathrm{~nm}$ ). Absorbance values at $356 \mathrm{~nm}$ were plotted against temperature and CMT was defined at the intersection point between the first inflection of the intensity and the successive sigmoidal curve progressively registered with increasing temperature.

\section{Design and characterization of KHP407-based sol-gel systems}

\section{Hydrogel preparation}

KHP407-based sol-gel systems were prepared within the concentration range 5$25 \% \mathrm{w} / \mathrm{v}$ by solubilizing KHP407 powder in PBS overnight at $4^{\circ} \mathrm{C}$.

\section{Characterization of the thermosensitive behavior of KHP407-based solutions}

\section{Tube inverting test}

Tube inverting test was conducted to estimate the LCGT of KHP407-based aqueous solutions. Each sample underwent a stepwise temperature increase from 5 to $55^{\circ} \mathrm{C}$. In each step, a $1{ }^{\circ} \mathrm{C}$ temperature 
increase was induced in the samples, temperature was kept constant for 5 minutes and finally the vials were inverted for their visual inspection. Sol and gel states were assessed by checking the presence or absence of flow within the 30 s of inversion. To eliminate results dependence over sample geometry, KHP407-based solutions (1 $\mathrm{mL})$ were prepared in Bijou vials $(17 \mathrm{~mm}$ inner diameter, CarloErba Reagents, Italy).

Tube inverting tests in isothermal conditions

Tube inverting test was also conducted in isothermal conditions at $37^{\circ} \mathrm{C}$ to estimate the time required for system gelation. Each sample (1 mL, Bijou vial), previously equilibrated at $4^{\circ} \mathrm{C}$, was incubated at $37^{\circ} \mathrm{C}$ and inverted (30 seconds) for the evaluation of its sol/gel condition every one minute.

\section{Rheological characterization}

Rheological characterization was carried out with a stress-controlled Anton Paar GmbH (Graz, Austria) MCR 302 rheometer carrying a plate/plate geometry $(50 \mathrm{~mm}$ in diameter) and a Peltier system. The trend of viscosity $v s$ temperature was registered by temperature ramp tests within the range 0 to $40^{\circ} \mathrm{C}\left(2^{\circ} \mathrm{C} / \mathrm{min}\right)$, by applying a constant shear rate $\left(0.1 \mathrm{~s}^{-1}\right)$ to the sample. Gel resistance to applied deformation was evaluated by strain sweep test at $37^{\circ} \mathrm{C}$, constant frequency $(10 \mathrm{~Hz})$ and strain within the range $0.01-500 \%$. The progressive gelation of the systems was assessed by frequency sweep tests, carried out at 25,30 and $37^{\circ} \mathrm{C}$, constant deformation within the linear viscoelastic (LVE) region and frequency ranging between 0.1 and $100 \mathrm{rad} / \mathrm{s}$. For each carried out test, the solution was slowly poured on the plate of the instrument at $0^{\circ} \mathrm{C}$ (gap $0.6 \mathrm{~mm}$ ), heated at the required temperature, equilibrated for 10 minutes and finally tested.

Gel swelling and stability to dissolution in aqueous media

Gel swelling and stability in simulated physiological conditions (aqueous media, $37^{\circ} \mathrm{C}$ ) were evaluated according to Boffito et al. ${ }^{19}$ Briefly, hydrogels were first prepared in Bijou vials $(0.8 \mathrm{~mL})$ and weighted $\left(\mathrm{w}_{\mathrm{i}}\right)$. After gelation at $37^{\circ} \mathrm{C}$ for 15 minutes, $0.8 \mathrm{~mL}$ of $\mathrm{PBS}$ (equilibrated at $37^{\circ} \mathrm{C}$ ) were added to each vial. The soaking medium was completely refreshed every two days. At predefined time points $(6,24,72,168$ and $336 \mathrm{~h}$ ), five samples were collected, the residual soaking medium was discarded and the hydrogels were weighted again $\left(\mathrm{w}_{\mathrm{f}}\right)$. To evaluate the stability of the gels in aqueous medium, the collected samples were lyophilized (Martin Christ ALPHA 2-4 LSC) and weighed again $\left(w_{\text {dried } f}\right)$. Samples not incubated in aqueous medium were also prepared and lyophilized to assess the initial dried weight of the gels $\left(\mathrm{w}_{\text {dried }}\right)$ ). Swelling and stability (i.e., polymer dissolution/degradation) were evaluated according to Eq. 1 and Eq. 2.

$$
\operatorname{swelling}(\%)=\frac{\left(w_{f}-w_{i}\right) \cdot 100}{w_{f}}
$$

$$
\text { polymer weight loss }(\%)=\frac{\left(w_{\text {dried } i}-w_{\text {dried } f}\right) \cdot 100}{w_{\text {dried. } i}}
$$

$$
\text { Eq. } 2
$$

\section{Gel injectability}

The injectability of the designed sol-gel systems at 5,25 and $37^{\circ} \mathrm{C}$ through G22, G18 and G14 needles was qualitatively evaluated by three potential users. Hydrogels were loaded in $2.5 \mathrm{~mL}$ plastic syringes and equilibrated at each analyzed temperature for 30 minutes before testing.

\section{Loading of model proteins into the hydrogels and characterization}

\section{Protein-loaded hydrogel preparation}

BSA and HRP were encapsulated in the hydrogels at a final concentration of 1 $\mathrm{mg} / \mathrm{mL}$. In order to load the biomolecules in the hydrogels, KHP407 was first solubilized in PBS using a $90 \%$ of the volume required to reach the selected polymer concentration in the final systems. The remaining $10 \%$ was added from a stock solution of BSA or HPR prepared in PBS at $10 \mathrm{mg} / \mathrm{mL}$. For instance, in order to prepare $1 \mathrm{~mL}$ of a gel with $15 \% \mathrm{w} / \mathrm{v}$ polymer concentration and 1 $\mathrm{mg} / \mathrm{mL}$ BSA content, $150 \mathrm{mg}$ of KHP407 were first weighted and solubilized in 900 $\mu \mathrm{L}$ of PBS at $4^{\circ} \mathrm{C}$ overnight. Then $100 \mu \mathrm{L}$ for a BSA stock solution previously prepared in PBS at $10 \mathrm{mg} / \mathrm{mL}$ were added to the hydrogel to reach a final KHP407 and BSA concentrations of $15 \% \mathrm{w} / \mathrm{v}$ and 1 $\mathrm{mg} / \mathrm{mL}$, respectively.

\section{Study of the effects of protein encapsula- tion of gel properties}

To assess possible effects of protein loading on gel stability and gelation potential, BSA- and HRP-loaded hydrogels were characterized as previously described for not-loaded gels.

\section{Characterization of protein release profile}

To evaluate the release capability of protein-loaded KHP407-based gels, samples $(0.8 \mathrm{~mL})$ were prepared in Bijou containers. After complete gelation (at $37^{\circ} \mathrm{C}$ for 15 minutes), $0.8 \mathrm{~mL}$ of PBS (equilibrated at $37^{\circ} \mathrm{C}$ ) was added to each gel and the systems were again incubated. At fixed time points $(1,3,5,24,48,72,168,240,336$ hours) the residual PBS was collected and $0.8 \mathrm{~mL}$ of fresh PBS was added. Protein content in the eluates was assessed through a BCA Protein Assay (Sigma Aldrich, Italy), according to supplier instructions. Absorbance at $562 \mathrm{~nm}$ was evaluated with a plate reader (Multimode Plate Reader VICTOR X3, PerkinElmer) and protein concentration was derived based on a calibration curve obtained with fresh BSA and HRP standards (concentration within 0.002 and 1 $\mathrm{mg} / \mathrm{mL}$, linearity found between 0.002 and $0.2 \mathrm{mg} / \mathrm{mL}$ ).

To characterize the protein release mechanism, Peppas equation was employed in the form reported in Eq. 3:

$$
\begin{array}{r}
\frac{M_{t}}{M_{\infty}}=k \cdot t^{n} \log \left(\frac{M_{t}}{M_{\infty}}\right)=n \cdot \log (t)+\log (k) \\
\text { Eq. } 3
\end{array}
$$

where $M_{t}$ and $M_{\infty}$ represent the quantity of molecule released at a predefined time $(\mathrm{t})$ and at infinite time, $\mathrm{k}$ is a constant related to system geometry and structural properties and $n$ is the release exponent. Depending on the values assumed by $n$, a different type of release can be identified: $n$ value of 0.45 or 0.89 indicates a diffusion-controlled (Fickian diffusion) or a swelling/relaxationcontrolled release, respectively, while a value in the range $0.45-0.89$ is indicative of a mixed behavior (anomalous transport).

\section{Evaluation of the residual activity of released horseradish peroxidase}

Residual activity of the released HRP was evaluated by TMB Substrate Kit (Sigma Aldrich, Italy). After appropriate dilution of the collected release media, TMB substrate was added to the samples at 2:1 volume ratio and incubated at RT for 30 minutes. The reaction was stopped by adding $\mathrm{HCl} 1 \mathrm{M}$ (1:1 volume ratio with respect to the sample) and absorbance was measured with a plate reader equipped with a filter at $395 \mathrm{~nm}$. Active HRP concentration in the samples was evaluated by comparison with fresh HRP standards in the concentration range $0.002-0.01 \mu \mathrm{g} / \mathrm{mL}$.

\section{Statistical analysis}

GraphPad Prism version 6.00 (GraphPad Software, La Jolla, CA, USA) was used for statistical analysis. Comparison among results was made by two-way ANOVA analysis and Tukey's multiple comparison test. Statistical significance was assessed according to Boffito et al. ${ }^{19}$ Results are expressed as mean \pm standard deviation. 


\section{Results and Discussion}

\section{Chemical Characterization of KHP407}

The successful synthesis of KHP407 was verified by ATR-FTIR and SEC. By comparing KHP407 and P407 ATR-FTIR spectra (Figure 1), the formation of urethane and urea bonds was immediately evident, with the appearance of new peaks at 3347 and $1722 \mathrm{~cm}^{-1}$, due to the stretching vibration of N-H bonds (amide II) and urethane/urea carbonyl groups $(\mathrm{C}=\mathrm{O}$, amide $\mathrm{I})$, respectively. An additional peak appeared at $1530 \mathrm{~cm}^{-1}$, due to the concurrent bending of $\mathrm{N}-\mathrm{H}$ (amide II) and stretching of C-N. Characteristic peaks of $\mathrm{P} 407$ were also identified (e.g., $\mathrm{CH}_{2}$ stretching and rocking at 2876 and $1242 \mathrm{~cm}^{-1}$, respectively, and -CO-C-stretching at $1097 \mathrm{~cm}^{-1}$ ), thus proving the formation of a P407-based PEU. Furthermore, no peak ascribed to unreacted diisocyanate groups was present within the range $2275-2250 \mathrm{~cm}^{-1}$. KHP407 weight average molecular weight $\left(\mathrm{M}_{\mathrm{w}}\right)$ measured by SEC was about $58 \mathrm{kDa}$ and the polydispersity index D was 1.8 .

\section{Characterization of KHP407 aggre- gation in aqueous medium}

DLS and DPH assay were performed on not-gelling KHP407-based aqueous solutions to characterize the temperature-driven assembling of the polymeric chains in micelles and micelle aggregates.

KHP407- and P407-based aqueous solutions added with the micellization dye DPH were subjected to a controlled temperature increase to evaluate their CMT, defined as the temperature associated to the first inflection observed in the graph that reports DPH absorbance at $356 \mathrm{~nm}$ vs temperature (Figure 2A).

Below CMT, the polymeric chains were not arranged into micelles and DPH showed almost no absorption within the analyzed spectral range; with increasing temperature over the CMT value, the polymer chains assembled into micelles, DPH was solubilized into their hydrophobic core and the absorbance at $356 \mathrm{~nm}$ increased. Additionally, DHP absorbance within the analyzed spectral range increased with temperature increase, proving the progressive micelle formation, and finally reached a plateau at the end of sample micellization. Table 1 reports CMT values of KHP407and $\mathrm{P} 407-$ aqueous solutions with concentration in the range $0.1-6 \% \mathrm{w} / \mathrm{v}$. As expected, CMT decreased with increasing polymer concentration, suggesting that polymer chain assembling into micelles starts at lower temperature in formulations with

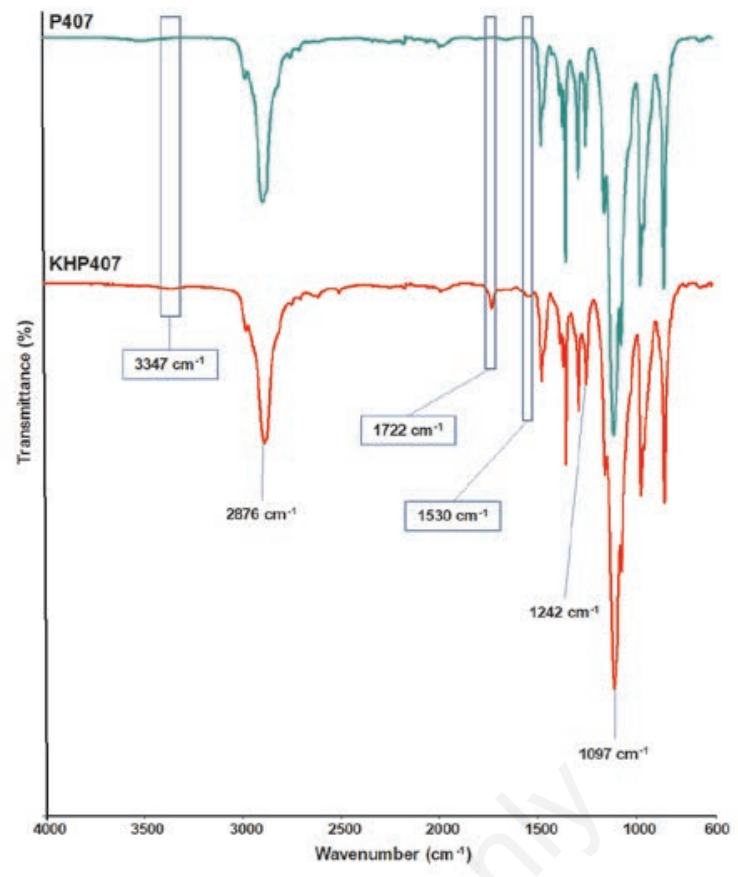

Figure 1. Attenuated Total Reflectance Fourier Transformed Infrared spectra of P407 (green) and KHP407 (red). Peaks at 2876, 1242 and $1097 \mathrm{~cm}^{-1}$ are typical of P407, while the appearance of peaks at 3347,1722 and $1530 \mathrm{~cm}^{-1}$ proved the formation of urethane bonds.

\section{(A)}

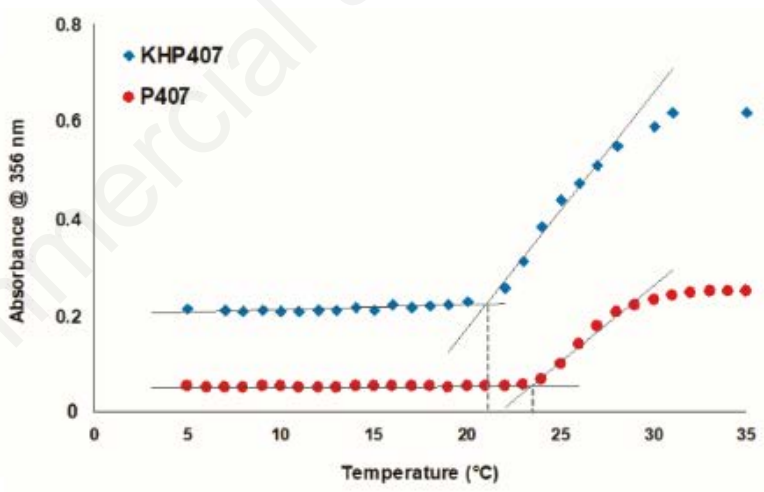

(B)

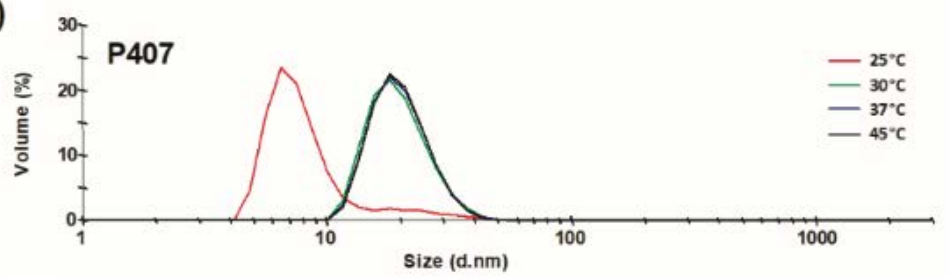

(C)

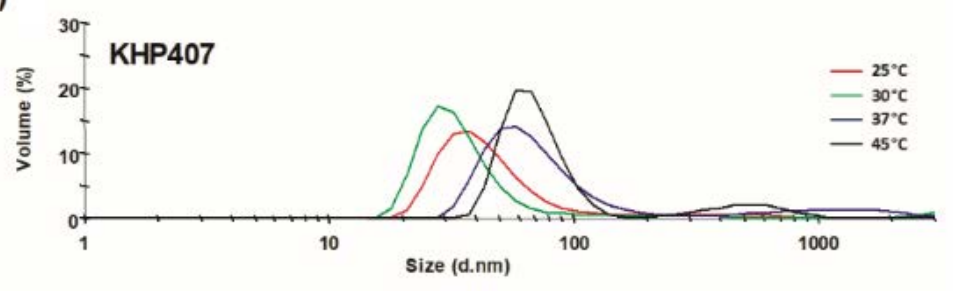

Figure 2. Characterization of KHP407 aggregation potential in aqueous medium. (A) DPH absorbance at $356 \mathrm{~nm}$ vs temperature of KHP407- and P407-based aqueous solutions with $1 \% \mathrm{w} / \mathrm{v}$ concentration; $(\mathrm{B})$ and $(\mathrm{C})$ volumetric distribution of the polymeric structures of $\mathrm{P} 407$ and KHP407 solutions at $1 \% \mathrm{w} / \mathrm{v}$ concentration, evaluated at 25, 30, 37 and $45^{\circ} \mathrm{C}$. 
higher concentration, as already reported in many studies. ${ }^{19-21}$ In addition, KHP407based solutions showed lower CMT values compared to P407-based compositions with the same weight/volume concentration (difference of approx. $1-2^{\circ} \mathrm{C}$, with the exception of $0.1 \% \mathrm{w} / \mathrm{v}$ concentrated sample). For instance, a CMT of $21^{\circ} \mathrm{C}$ was estimated for KHP407 and P407 solutions with $1 \% \mathrm{w} / \mathrm{v}$ $(0.17 \mathrm{mM})$ and $3 \% \mathrm{w} / \mathrm{v}$ (approx. $3 \mathrm{mM}$ ), respectively, suggesting that KHP407 polymer chains in solution were able to assemble into micelles at much lower molar concentration compared to P407 ones. Hence, in KHP407-based samples, the thermodynamic conditions required for the onset of micellization are reached at lower concentrations, as a consequence of the increased molecular weight and the introduction of hydrophobic blocks (i.e., HDI moieties) along the polymer backbone, which allow to achieve the degree of dehydration required for micelle formation at lower concentrations.

KHP407 and P407 samples at 0.5 and $1 \% \mathrm{w} / \mathrm{v}$ concentration were also characterized in terms of hydrodynamic diameter at three different temperatures to assess the dimension of the polymeric aggregates (i.e., unimers, micelles and micelle aggregates) and their volumetric distribution within the samples, as well as the dependence of these results over temperature. For instance, Figure $2 \mathrm{~B}$ and $\mathrm{C}$ reports the volumetric distribution of the polymeric structures of P407 and KHP407 solutions at 1\% w/v, evaluated at $25,30,37$ and $45^{\circ} \mathrm{C}$. At $25^{\circ} \mathrm{C}$, $1 \% \mathrm{w} / \mathrm{v}$ concentrated $\mathrm{P} 407$ sample exhibited both unimers $(5.8 \pm 0.4 \mathrm{~nm})$ and micelles $(21.9 \pm 0.4 \mathrm{~nm})$, with a volumetric content of $88.2 \pm 1.6 \%$ and $11.6 \pm 1.6 \%$, respectively. As expected, with increasing temperature, a progressive reorganization of $\mathrm{P} 407$ unimers into micelles took place with a $100 \%$ content of micelles starting from a temperature of $30^{\circ} \mathrm{C}$. Regarding micelle size, a slight decrease in micelle hydrodynamic diameter was observed with increasing temperature $(21.9 \pm 0.4 \mathrm{~nm}$ and $20.5 \pm 0.3 \mathrm{~nm}$ at 25 and $45^{\circ} \mathrm{C}$, respectively), as a consequence of PEO dehydration, in accordance with already published results. 22 In the case of KHP407-based aqueous solution, no unimers were detected at $25^{\circ} \mathrm{C}$ and the polymeric chains turned out to be almost completely ( $83.2 \pm 4.7 \%$ in volume) assembled into micelles with a hydrodynamic diameter of $39.4 \pm 6.7 \mathrm{~nm}$, while few micelle aggregates (approx. 3\% in volume) were already present with an average size of $419.2 \pm 22.8 \mathrm{~nm}$. Clustering and aggregation phenomena prenominated with increasing temperature in KHP407-based aqueous solutions, reaching an average hydrody- namic diameter of $553.7 \pm 34.8 \mathrm{~nm}$ and a volumetric content of $11.9 \pm 0.5 \%$ at $45^{\circ} \mathrm{C}$. In agreement with previous observations, 19,23 the average hydrodynamic diameter of P407-based micelles was independent over sample concentration (at $30^{\circ} \mathrm{C}$, the diameter of $\mathrm{P} 407$ micelles assembled in aqueous solutions with 0.5 and $1 \% \mathrm{w} / \mathrm{v}$ concentrations was $21.3 \pm 3.6 \mathrm{~nm}$ and $19.6 \pm 0.6$ $\mathrm{nm})$. At $25^{\circ} \mathrm{C}$, the sample with $0.5 \% \mathrm{w} / \mathrm{v}$ concentration was almost completely in the form of unimers (approx. 99\% in volume), while the $1 \% \mathrm{w} / \mathrm{v}$ concentrated solution already contained micelles (approx. the $10 \%$ in volume), in accordance with the lower CMT of $1 \% \mathrm{w} / \mathrm{v}$ concentrated sample compared to the $0.5 \% \mathrm{w} / \mathrm{v}$ concentrated one. This slight difference disappeared at $30^{\circ} \mathrm{C}$, with $\mathrm{P} 407$ polymer chains almost completely assembled in the form of micelles $(100 \%$ and $98.9 \pm 1.2 \%$ in volume for P407-based solution at 1 and $0.5 \% \mathrm{w} / \mathrm{v}$ concentration, respectively) for both the analyzed solutions, as they were already over their CMT. In accordance with our previous data on a similar poly(ether urethane), ${ }^{19}$ in KHP407-based samples a dependence of hydrodynamic diameter over sample concentration was observed, probably due to the enhanced aggregation phenomena present in KHP407 solutions compared to P407-based ones with the same concentration. For instance, at $45^{\circ} \mathrm{C}$ KHP407-based structures showed a size of $69.9 \pm 1.1 \mathrm{~nm}$ and $50.9 \pm 4.3 \mathrm{~nm}$ $(0.001<\mathrm{P}<0.01)$ in solutions with 0.5 and $1 \% \mathrm{w} / \mathrm{v}$ concentration, respectively. At the same temperature, bigger aggregates were also present, with smaller size and lower

Table 1. Critical Micellization Temperature (CMT) values of P407 and KHP407 solutions with concentration ranging between 0.1 and $6 \% \mathrm{w} / \mathrm{v}$. Error: $\pm 1^{\circ} \mathrm{C}$.

\begin{tabular}{lcc} 
Concentration $(\%$ w/v $)$ & P407 & CVIT $\left({ }^{\circ} \mathrm{C}\right)$ \\
0.1 & 29 & 24 \\
0.5 & 24 & 22 \\
\hline 1 & 23 & 21 \\
3 & 21 & 20 \\
\hline 5 & 19 & 18 \\
6 & 18 & 17 \\
\hline
\end{tabular}

Table 2. Lower critical gelation temperature (LCGT) and gelation time in physiological conditions $\left(37^{\circ} \mathrm{C}\right)$ of $\mathrm{KHP} 407$ aqueous solutions with concentration within the range 5$25 \% \mathrm{w} / \mathrm{v}$. Error: $\pm 1^{\circ} \mathrm{C}$ for LCGT values, \pm 1 minute for gelation time results.

\begin{tabular}{lccccccccccc} 
Concentration $(\% \mathrm{w} / \mathrm{v})$ & 5 & 6 & 8 & 10 & 12 & 15 & 18 & 20 & 22 & 25 \\
LCGT $\left({ }^{\circ} \mathrm{C}\right)$ & $-*$ & 38 & 34 & 31 & 28 & 25 & 23 & 22 & 20 & 17 \\
Gelation Time at $37^{\circ} \mathrm{C}(\mathrm{min})$ & $\mathrm{x}^{* *}$ & $\mathrm{x}^{* *}$ & 11 & 9 & 9 & 5 & 4 & 4 & 3 & 3 \\
\hline
\end{tabular}

*no gelation observed within the analyzed temperature range; ${ }^{* *}$ not tested samples. volumetric content in the $0.5 \% \mathrm{w} / \mathrm{v}$ concentrated solution $(393.8 \pm 59.6 \mathrm{~nm}, 3.1 \pm 1 \%)$, as expected.

\section{Characterization of the thermosensi- tive behavior of KHP407-based solu-} tions

\section{Tube inverting test}

A qualitative estimation of LCGT valout on KHP407-based solutions prepared in $\mathrm{PBS}$, with concentrations in the range 4$25 \% \mathrm{w} / \mathrm{v}$ (Table 2).

Although the test was carried out up to , no gel-to-sol transition was observed, systems in a wide temperature window. KHP407-based solutions with 5\% w/v concentration were found to be below the critical gelation concentration (CGC), which identifies the minimum concentration requested to observe gelation. Hence, 407-based sol-gel systems showed a ing concentration, LCGT values decreased, with the samples prepared at the highest considered concentrations (22 and 25\% $\mathrm{w} / \mathrm{v}$ ) undergoing a sol-to-gel transition below RT (20 and $17^{\circ} \mathrm{C}$, respectively). Despite the qualitative nature of this test, no differences in LCGT and CGC vious observations on sol-gel systems prepared starting from poly(ether urethane)s differing from KHP407 only for their chain extender (N-Boc serinol and 1,4-cyclohexanedimethanol instead of L-Lysine ethyl , 19,24 thus suggesting that this block does not play the leading role in determin- 
ing the properties of the whole polymer.

Tube inverting test was repeated also in isothermal conditions at $37^{\circ} \mathrm{C}$, to estimate gelation time in physiological conditions after injection; all systems with a LCGT value below this temperature transitioned to a gel state within 11 minutes, with the compositions showing the highest PEU concentrations reaching a complete gelation in 3 minutes.

After these preliminary evaluations, three systems, differing in the concentration of the starting polymeric solution, were selected to be further characterized. Selection was made taking into account the main requirements to design an in situ gelling system suitable for drug delivery applications, such as i) fast and complete gelation at body temperature within few minutes, ii) easy injectability/workability in the sol/biphasic state, and iii) possibility to finely tune residence time, release kinetics and profile. Sol-gel systems with a KHP407 concentration of 8,15 and $18 \% \mathrm{w} / \mathrm{v}$ were thus selected for further characterization, since they showed LCGT values ranging between RT and $35^{\circ} \mathrm{C}$, and fast gelation in physiological conditions (within the range 4-11 minutes). Additionally, they are expected to exhibit quite different rheologi- cal properties and residence times, which could make them suitable to different applications (e.g., localized injection in tissues, direct application on skin bed) and allow a fine modulation of the release of an encapsulated payload. The selected systems will henceforth be referred as KHP407_8\% w/v, KHP407 15\% w/v and KHP407_18\% w/v respectively.

\section{Rheological characterization of KHP407- based sol-gel systems}

The temperature-driven sol-to-gel transition of KHP407 aqueous solutions was quantitatively characterized by rheological tests. In detail, the trend of viscosity $v s$ temperature was assessed by temperature ramp tests within the temperature range from 0 to $40^{\circ} \mathrm{C}$ (Figure 3D). System viscosity initially decreased as typical of fluids, with the exception of KHP407 8\%w/v sol-gel system which showed a noisier signal due to its very low viscosity $\left(20 \mathrm{mPa} \cdot \mathrm{s}\right.$ at $\left.0^{\circ} \mathrm{C}\right)$. Then, after the achievement of a minimum value, viscosity sharply increased as a result of the progressive micelle nucleation and reorganization into a gel network. The temperature associated to viscosity inflection was defined as the onset of the gelation process $\left(\mathrm{T}_{\text {onset }}\right)$. Although a plateau value of viscosity was expected at the end of gelation, all the analyzed samples underwent melt fracture, in accordance with our previous data on similar sol-gel systems. ${ }^{19}$ Table 3 reports the characteristic parameters of temperature ramp tests, highlighting that both viscosity and $\mathrm{T}_{\text {onset }}$ are strongly related to hydrogel concentration, with the former increasing and the latter decreasing with increasing the concentration of the gelling solution, in agreement with tube inverting tests results.

The progressive gelation of KHP407 8\% w/v, KHP407 15\% w/v and KHP407_18\% w/v was also characterized by frequency sweep tests at 25,30 and $37^{\circ} \mathrm{C}$ (Figure 3A, B and C). As characteristic parameters of frequency sweep tests, storage (G') and loss (G') moduli values at 100 $\mathrm{rad} / \mathrm{s}$ and the frequency value at $\mathrm{G}^{\prime} / \mathrm{G}$ " crossover $\left(\omega_{\mathrm{G}} / \mathrm{G}^{\prime}\right.$ " crossover $)$ are reported in Table 3 for each composition at each considered temperature. The crossover frequency moved to lower values with temperature increase, as a consequence of the progressive gelation of the systems, encompassing the biphasic state in which the gel and sol states coexist. At the same temperature, the crossover frequency turned out to be affected by sample concentration, with lower values in hydrogels with higher concentration. Hence, with increasing hydrogel polymer
(A)

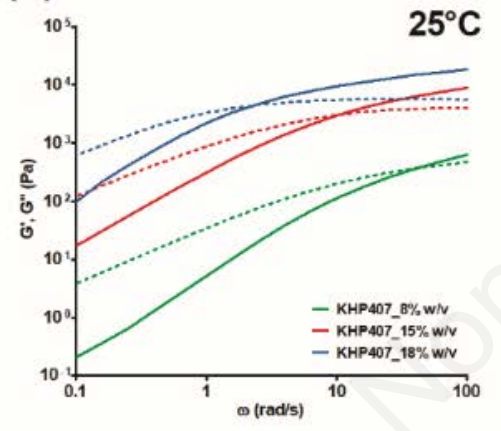

(D)

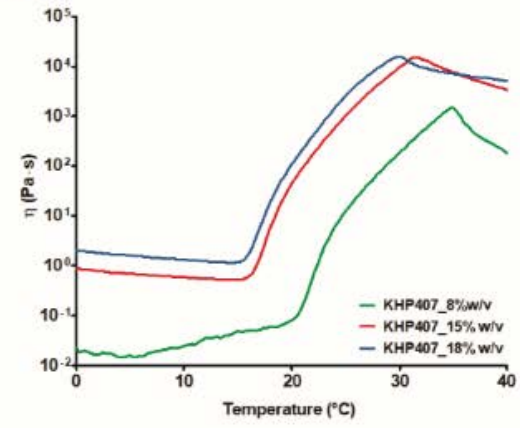

(B)

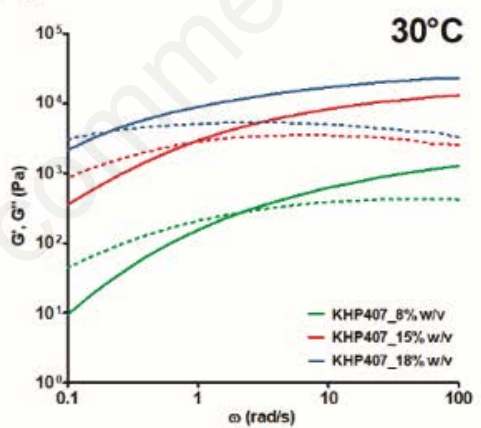

(E)

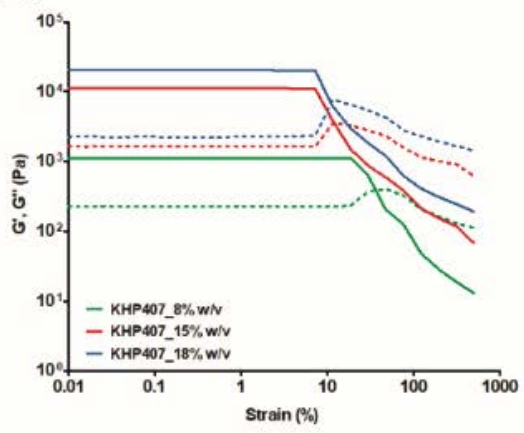

(C)

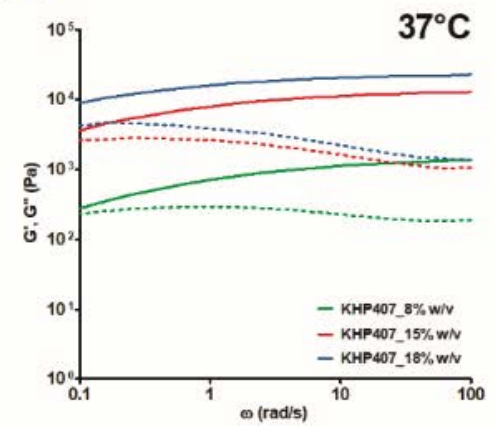

(F)

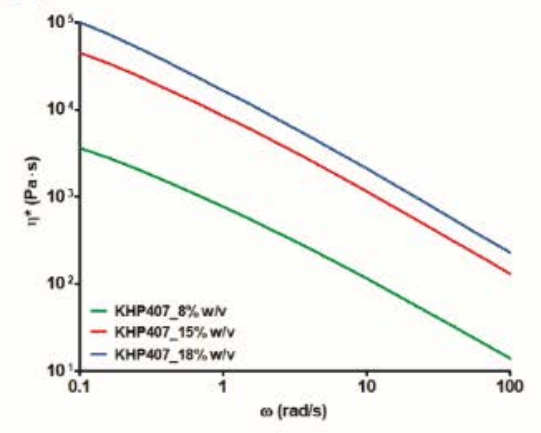

Figure 3. Results of rheological characterizations of KHP407_8\% w/v, KHP407_15\% w/v and KHP407_18\% w/v. (A), (B) and (C) storage (G', continuous line) and loss (G”, dashed line) moduli trend as a function of frequency $(\omega)$ evaluated at 25,30 and $37^{\circ} \mathrm{C}$; (D) trend of viscosity $(\eta)$ vs temperature as assessed by temperature ramp tests; (E) G' (continuous line) and G" (dashed line) trend as a function of applied deformation, evaluated at $37^{\circ} \mathrm{C}$; (F) trend of complex viscosity $\left(\eta^{*}\right)$ vs frequency at $37^{\circ} \mathrm{C}$. 
content, the kinetics of the transition from the sol to the gel state became faster, in accordance with the lower $\mathrm{T}_{\text {onset }}$ of these systems. At $37^{\circ} \mathrm{C}$, none of the analyzed samples showed a $\mathrm{G}^{\prime} / \mathrm{G}^{\prime}$ " crossover within the considered frequency range, suggesting that all the systems were in the gel state. However, a further temperature increase would be required to observe the typical behavior of fully developed gels, characterized by G' values independent over frequency. Strain sweep tests showed the typical trend of associative polymeric structures. Figure 3E reports the trend of G' and G' as a function of applied strain $(\gamma)$ for each analyzed gel measured at $37^{\circ} \mathrm{C}$, while Table 3 summarizes the characteristic parameters of this analysis, i.e., the LVE, defined as the maximum strain the system can be subjected to before the breakage of its structure (i.e., no decrease in G') and the Yield Stress (YS), evaluated at G" maximum. Gel resistance to applied deformation decreased with increasing hydrogel polymer concentration, due to the higher degree of network organization of KHP407_15\% w/v and KHP407_18\% w/v compared to KHP407_8\% w/v. After the LVE value was reached, loss modulus started to increase with increasing applied deformation up to a maximum value, followed by a progressive decrease. Between the end of the LVE and G" maximum, only micro-cracks occurred in the samples, while after G" maximum was exceeded a macro-crack developed in the sample and the viscous portion of the viscoelastic behavior started to prevail (G'> G', fluid state).

\section{Gel swelling and stability to dissolution in aqueous media}

Stability tests were performed at $37^{\circ} \mathrm{C}$ in aqueous environment to simulate physiological conditions. PBS absorption and polymer dissolution/degradation phenomena were studied as a function of time, by evaluating sample weight changes according to Eq. 1 and 2. Figure 4A and B report the percentage of swelling and dissolution in aqueous medium of KHP407-based systems with 8,15 and $18 \% \mathrm{w} / \mathrm{v}$ concentration at different time points. KHP407_8\% w/v samples, after a slight increase in PBS absorption at 6 hours incubation time, started to be dominated by dissolution phenomena, as assessed by the negative weight change of swollen samples after 3 days of incubation. The same trend was confirmed in terms of gel dissolution, with a weight loss of $37 \pm 4 \%$ at 3 days. KHP $407 \_8 \% \mathrm{w} / \mathrm{v}$ dissolution was almost complete after 8 days of incubation in aqueous medium $(83 \pm 18 \%)$, with the high standard deviation value proving the high instability of these
Table 3. Characteristic parameters of rheological characterization. Viscosity at $\mathbf{0}$ and $25^{\circ} \mathrm{C}\left(\eta_{0^{\circ} \mathrm{C}}, \eta_{25^{\circ}} \mathrm{C}\right)$, temperature onset of the transition for the sol to the gel state $\left(\mathrm{T}_{\mathrm{onset}}\right)$, crossover frequency of G' and $G^{\prime \prime}\left(\omega_{G^{\prime} / G^{\prime} \text { c crossover }}\right)$ and $G^{\prime}$ and $G^{\prime \prime}$ values at $100 \mathrm{rad} / \mathrm{s}(\mathrm{at}$ 25,30 and $37^{\circ} \mathrm{C}$ ), extension of the linear viscoelastic region (LVE) and Yield stress (YS) of KHP407-based formulations with 8,15 and $18 \% \mathrm{w} / \mathrm{v}$ polymer concentration.

\begin{tabular}{lcccc} 
Concentration $(\% \mathrm{w} / \mathrm{v})$ & & 8 & 15 & 18 \\
$\eta_{0^{\circ} \mathrm{C}}(\mathrm{Pa} \mathrm{s})$ & & 0.02 & 0.9 & 1.9 \\
$\mathrm{~T}_{\text {onset }}\left({ }^{\circ} \mathrm{C}\right)$ & 16.7 & 14.7 & 14.4 \\
\hline$\eta_{25^{\circ} \mathrm{C}}(\mathrm{Pa} \mathrm{s})$ & & 13 & 1040 & 2610 \\
$\omega_{\mathrm{G}^{\prime} / \mathrm{G}^{\prime} \text { crossover }(\mathrm{rad} / \mathrm{s})}$ & $25^{\circ} \mathrm{C}$ & 42.2 & 10.4 & 2.3 \\
& $30^{\circ} \mathrm{C}$ & 2.2 & 0.9 & 0.2 \\
& $37^{\circ} \mathrm{C}$ & - & - & - \\
\hline $\mathrm{G}^{\prime} / \mathrm{G}^{\prime} 100 \mathrm{rad} / \mathrm{s}(\mathrm{Pa})$ & $25^{\circ} \mathrm{C}$ & $624 / 468$ & $8830 / 3940$ & $18300 / 5520$ \\
& $30^{\circ} \mathrm{C}$ & $1270 / 420$ & $13100 / 2550$ & $23300 / 3270$ \\
& $37^{\circ} \mathrm{C}$ & $1380 / 187$ & $12900 / 1070$ & $22800 / 1370$ \\
$\mathrm{LVE}(\%)$ & & 18.6 & 7.3 & 7.3 \\
\hline $\mathrm{YS}(\mathrm{Pa})$ & & 216 & 598 & 1110 \\
\hline
\end{tabular}

(A)

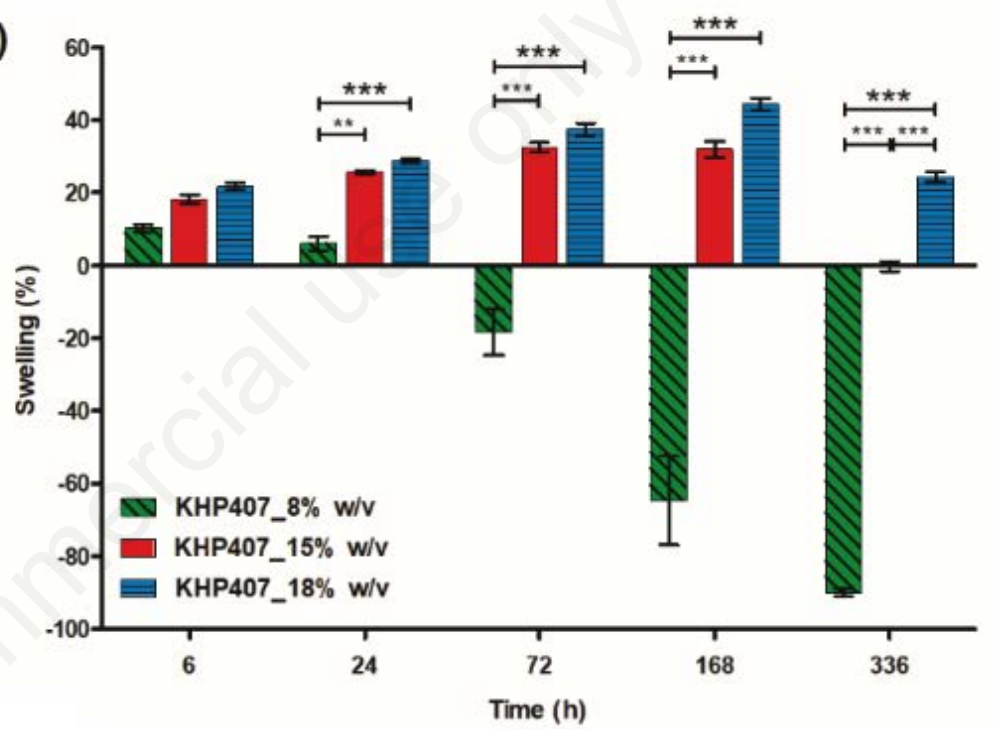

(B)

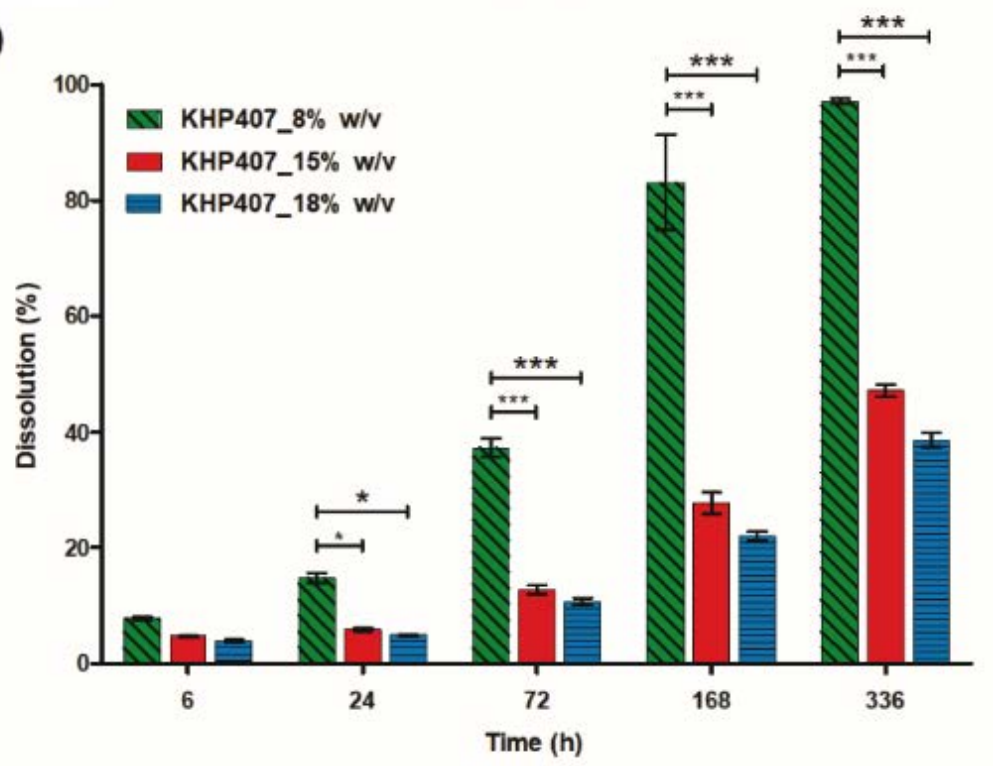

Figure 4. Percentage of swelling (A) and polymer dissolution (B) of KHP407_8\% w/v, KHP407_15\% w/v and KHP407_18\% w/v, evaluated at 6, 24, 72, 168 and 336 hours of incubation in aqueous medium. 
systems. KHP407 15\% w/v and KHP407 18\% w/v systems, on the other hand, showed better long-term stability; PBS absorption showed a progressive increase up to 8 days of incubation for both the analyzed compositions, reaching values of $34 \pm 2 \%$ and $44 \pm 4 \%$, respectively, with weight loss of $28 \pm 4 \%$ and $22 \pm 2 \%$. After 14 days, however, a reduction in PBS absorption was observed, suggesting that dissolution phenomena started to overcome swelling. This decrease was significantly higher for KHP407_15\% w/v systems compared to KHP407_18\% w/v, suggesting a higher loss in stability. However, weight loss values were still relatively low $(47 \pm 2 \%$ for KHP407 $15 \% \mathrm{w} / \mathrm{v}$ and $39 \pm 3 \%$ for KHP407 18\% w/v) and the gels were found to have retained their cylindrical shape. A statistically significant $(\mathrm{P}<0.001)$ difference in PBS absorption and weight loss was observed between KHP407_8\% w/v gels and the other two systems (after 1 day incubation with KHP407 18\% w/v and 3 days incubation with KHP407_15\% w/v).

\section{Gel injectability}

The injectability of KHP407-based hydrogels was qualitatively tested at different temperatures using commercially available $2.5 \mathrm{~mL}$ syringes equipped with needles differing in their inner diameter (G22, G18 and $\mathrm{G} 14$ ). At $5^{\circ} \mathrm{C}$, all the formulations were completely in the sol state and thus easily extruded through all the needles. By increasing temperature, the viscosity of the hydrogels started to increase as a result of the progressive transition from the sol to the gel state. For KHP407_8\% w/v hydrogels, this effect was not so relevant, and they remained easily injectable at 25 and $37^{\circ} \mathrm{C}$. On the other hand, gels with higher concentrations became progressively more difficult to extrude and both KHP407_15\% w/v and KHP407 18\% w/v systems resulted not to be injectable through the smallest needle (G22) at $37^{\circ} \mathrm{C}$, due to their high viscosity and almost complete transition to the gel state at this temperature (Figure 3). As a matter of fact, by plotting the trend of complex viscosity $\left(\eta^{*}\right)$ as a function of frequency at $37^{\circ} \mathrm{C}$ (Figure $3 \mathrm{~F}$ ), all the tested samples showed a typical shear thinning behavior, with KHP407_15\% w/v and KHP407_18\% w/v showing complex viscosity values one or two orders of magnitude higher with respect to KHP407 8\% $\mathrm{w} / \mathrm{v}$, within the whole frequency range analyzed (at $0.1 \mathrm{rad} / \mathrm{s}$, KHP407 $8 \% \mathrm{w} / \mathrm{v}$, KHP407_15\%w/v and KHP407_18\%w/v showed complex viscosity value of 3600 , 44800 and $99800 \mathrm{~Pa} \cdot \mathrm{s}$, respectively).

\section{Characterization of protein loaded hydrogels}

\section{Study of the effects of protein encapsula- tion of gel properties}

The encapsulation of the selected model proteins (BSA and HRP) within the hydrogels at a concentration of $1 \mathrm{mg} / \mathrm{mL}$ turned out not to affect the overall gel properties at a large extent. For instance, tube inverting test performed on KHP407 8\% w/v, KHP407_15\% w/v and KHP407_18\% w/v samples loaded with BSA and HRP resulted in LCGT values of 35,26 and $23^{\circ} \mathrm{C}$, respectively, demonstrating that protein encapsulation does not affect hydrogel gelation potential and gelation temperature. A similar trend was observed in tube inverting test carried out in isothermal conditions at $37^{\circ} \mathrm{C}$, that showed gelation times for both BSAand HRP-loaded gels within the range 3-11 minutes (11, 5 and 3 minutes for gels with KHP407 concentration of 8, 15 and $18 \%$ $\mathrm{w} / \mathrm{v}$, respectively). As expected, no differences were detected between BSA- and HRP-loaded hydrogels, being both the analyzed proteins globular, water soluble, and characterized by molecular weight in the order of tens Da (44000 and $66000 \mathrm{Da}$ for HRP and BSA, respectively) and almost the same hydrodynamic diameter (approx. 8.0 and $7.5 \mathrm{~nm}$ for HRP and BSA, respective1y). 25,26 To further confirm these results, rheological characterization was also performed. Both strain and frequency sweep tests evidenced no significant differences in the LVE and YS values (e.g., KHP407_18\% $\mathrm{w} / \mathrm{v}$, BSA-loaded KHP407 18\% w/v and HRP-loaded KHP407_18\% w/v showed LVE of $7.25 \%$ and YS of 1115,1080 and $1050 \mathrm{~Pa}$, respectively), as well as in the frequency value at $\mathrm{G}^{\prime} / \mathrm{G}^{\prime}$ ' crossover (e.g., at $30^{\circ} \mathrm{C}$ KHP407_18\% w/v, BSA-loaded KHP407_18\% w/v and HRP-loaded KHP407_18\% w/v gels exhibited $\omega_{\mathrm{G}} / \mathrm{G}$, crossover of $0.21,0.30$ and $0.32 \mathrm{rad} / \mathrm{s}$, respectively). The slight decrease in YS and increase in $\omega_{\mathrm{G}^{\prime} / \mathrm{G}}$ " crossover values observed upon protein encapsulation could be ascribed to a sort of hampering effect, induced by the proteins which act as small defects in the gel network, slowing down the kinetics of micelle packing and organization. However, to further confirm this hypothesis rheological characterization of hydrogels loaded with a higher amount of proteins should be performed.

Similarly, swelling and stability to dissolution in aqueous media tests showed no significant differences between the analyzed samples, confirming PBS absorption and dissolution trends found for non-loaded systems. For instance, after 3 days of incubation in aqueous medium, KHP407_18\% w/v, BSA-loaded KHP407_18\% w/v and HRP-loaded KHP407_18\% w/v showed a percentage of swelling of $37.4 \pm 3.8 \%$, $37.8 \pm 1.3 \%$ and $37.7 \pm 1.2 \%$, and a polymer dissolution degree of $10.7 \pm 1.4 \%, 9.1 \pm 1.2 \%$ and $10.5 \pm 0.7 \%$, respectively.

\section{Characterization of protein release profile}

The release profiles of BSA and HRP from KHP407 8\% w/v, KHP407 15\% w/v and KHP407_18\% w/v gels are reported in Figure $5 \mathrm{~A}$ and $\mathrm{B}$.

A hydrogel concentration-dependent release was observed for both proteins. In detail, for KHP407_8\% w/v gels, the release was faster compared to the other two compositions and was almost completed after 3 days of incubation $(86 \pm 2 \%$ for BSA and $92 \pm 3 \%$ for HRP). This kinetics is in accordance with the poor stability in aqueous environment of these systems, as assessed previously. Hydrogels with higher polymer concentrations (i.e., 15 and 18\% $\mathrm{w} / \mathrm{v}$ ), on the other hand, showed a more sustained release in the timeframe considered, with an almost complete release of both the proteins after 14 days. For instance, HRP release reached $95 \pm 7 \%$ and $88 \pm 5 \%$ of the encapsulated drug from KHP407_15\% w/v and KHP407_18\% w/v, respectively. No significant differences were observed between the release kinetics of the two proteins, in accordance with the previously reported data on the characterization of protein-loaded gels. On the other hand, statistical differences $(\mathrm{P}<0.001)$ were observed by comparing the release from KHP407_8\% w/v gels with KHP407_15\% w/v and KHP407 18\% w/v samples within the timeframe of 5 hours- 3 days. Protein release from KHP407_15\% w/v systems was statistically higher compared to KHP407_18\% w/v gels within 3 and 10 days observation times ( $\mathrm{P}<0.001$ for HRP-loaded samples).

Finally, Peppas equation was exploited to better characterize the release mechanism of the designed hydrogels. The release exponent $\mathrm{n}$ was estimated within the timeframe of 1-5 hours; after that, dissolution phenomena started to be prevalent, especially for KHP407_8\% w/v systems, thus making the calculated values not consistent. For all the concentrations and for both proteins, $\mathrm{n}$ values were ranging between 0.45 (diffusion-controlled release) and 0.89 (swelling-controlled release), indicating that both mechanisms are involved in controlling the release kinetics. As expected, however, $\mathrm{n}$ values were higher $(0.78 \pm 0.10$ for BSA and $0.78 \pm 0.02$ for HRP) for the 
hydrogels with the lowest concentration (KHP407_8\% w/v), while the release exponent was lower for KHP407_15\% w/v and KHP407_18\% w/v gels, with values around 0.6 , indicating a more diffusive-controlled release mechanism for these systems. As an example, regarding BSA release, a statistically relevant difference $(\mathrm{P}<0.001)$ was found between $\mathrm{n}$ values calculated for KHP407_8\% w/v $(0.78 \pm 0.10) \quad$ and KHP407_15\% w/v $(0.48 \pm 0.08)$ gels.

\section{Evaluation of the residual activity of released horseradish peroxidase}

With the final aim of designing delivery systems that could be used as carriers for biomolecule transportation, the ability of the developed KHP407-based gels to release proteins able to maintain their biological activity was preliminary assessed by evaluating the residual activity of the released HRP through a colorimetric assay. The release profile of functional HRP from KHP407_8\% w/v, KHP407_15\% w/v and KHP $407-18 \% \mathrm{w} / \mathrm{v}$ is reported in Figure $5 \mathrm{C}$. Active HRP was released up to approximately 2 days, with an initial burst release around $20 \%$ within the first 5 hours. Hence, after 5 hours incubation in aqueous media, approx. the $57 \%$ of the total HRP released from KHP407_8\% w/v was delivered in its active form. Differently, in the case of KHP407_15\% w/v and KHP407_18\% w/v no loss in activity was detected up to 5 hours release time. Starting from day 2, almost no further enzymatic activity was detected in all the eluates, so that the total amount of active HRP released from the gels ranged between 30 and $40 \%$ of the initially encapsulated amount, which is comparable with other literature studies. ${ }^{27,28}$ By comparing the results of the two conducted colorimetric tests, we demonstrated by BCA assay that the actual amount of released HRP was in fact higher (Figure 5A) compared to the amount of active HRP detected by TMB assay and in accordance with the kinetics shown by BSA. Hence, the relatively small quantity detected by TMB assay implies a partial inactivation of the released enzyme, instead of an incapability of the gels to release their payload. Nevertheless, up to 1 day incubation, KHP407_15\% w/v and KHP407_18\% w/v systems were able to release HRP almost completely in its active form, while in the case of KHP407_8\% w/v gels, only the 40 $50 \%$ of the release HRP was in its functional structure. These results suggest that HRP inactivation cannot be correlated to the encapsulation process itself, which in fact was carried out in mild conditions, but rather to the interaction between the enzyme and the free polyurethane chains dispersed in the eluates after the gels started
(A)

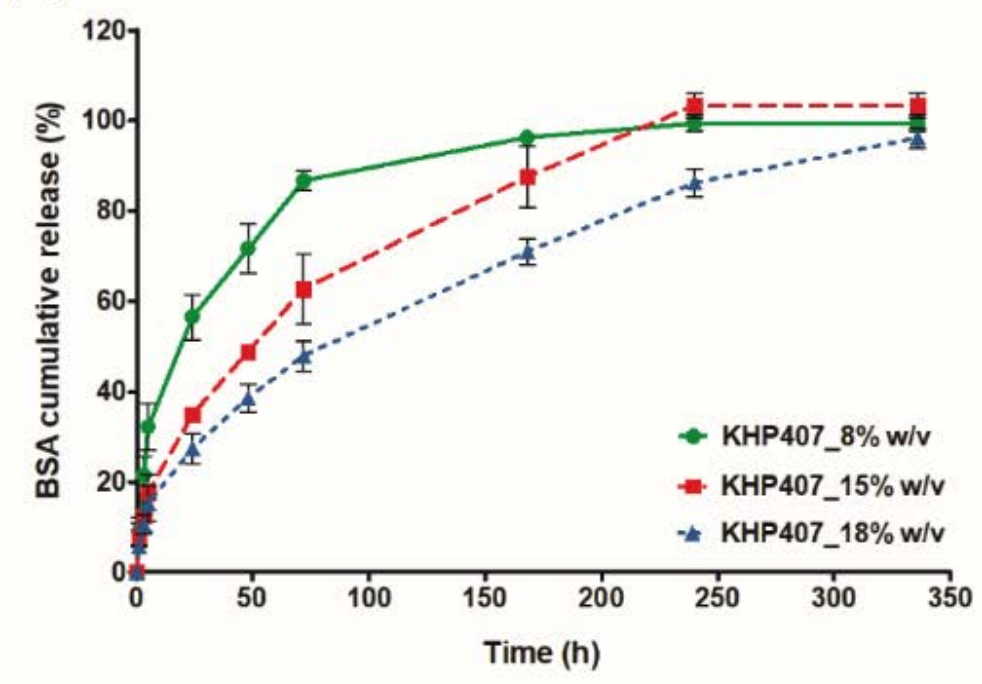

(B)

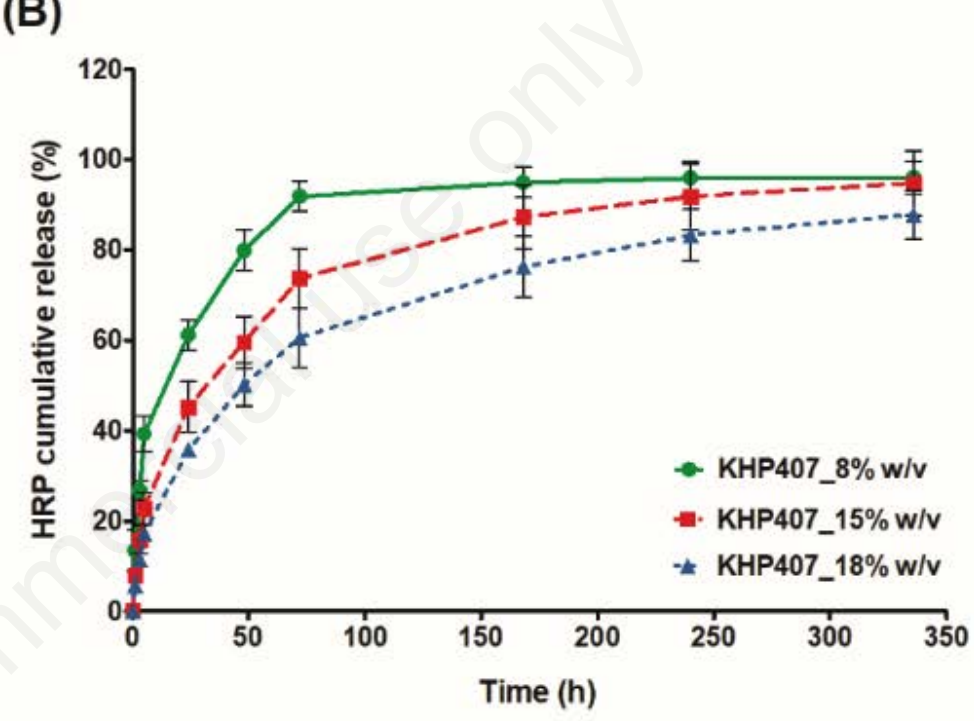

(C)

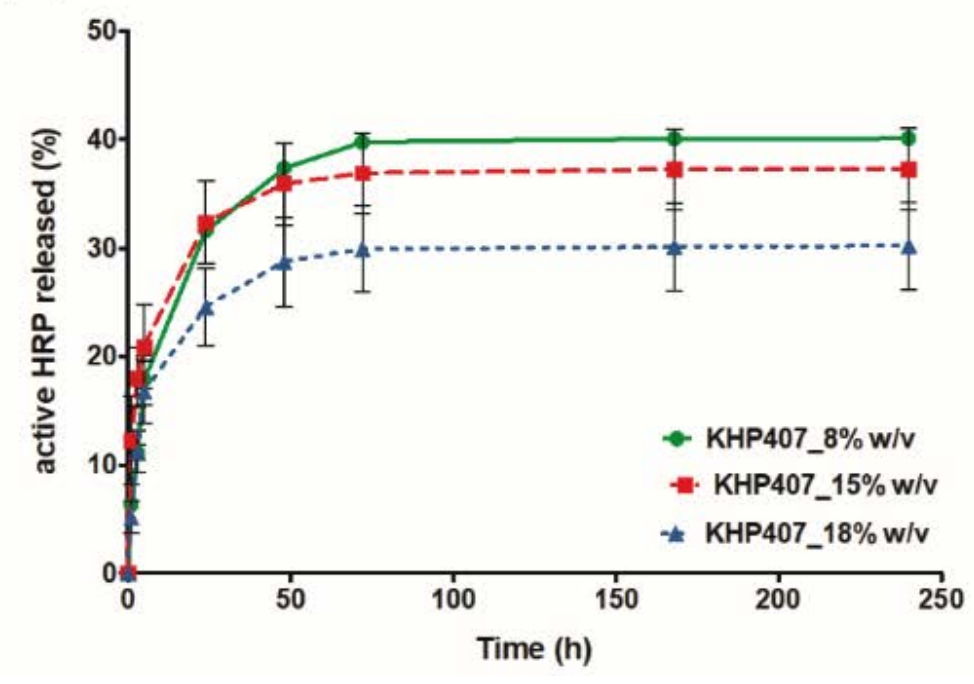

Figure 5. Cumulative release profile (\%) of bovine serum albumin (BSA) (A), and horseradish peroxidase (HRP) (B), from KHP407_8\% w/v, KHP407_15\% w/v and KHP407_18\% w/v as assessed by BCA colorimetric assay; (C) Cumulative release profile (\%) of active HRP from KHP407_8\% w/v, KHP407_15\% w/v and KHP407_18\% w/v as assessed by $3,3^{\prime}, 5,5^{\prime}$-Tetramethylbenzidine colorimetric assay. 
to dissolve. Amphiphilic polymers have indeed been found to cause conformational changes in protein structures that could be responsible for the progressive inactivation of the enzyme; additionally, small polymer chains could form hydrogen bonds with the enzyme active site, thus preventing its reaction with the substrate given by the activity test. ${ }^{29}$ As a matter of fact, to support this hypothesis, the inactivation effect was more prominent for KHP407_8\% w/v hydrogels, that according to the previously discussed stability tests lost about $15 \%$ of their initial weight after 1 day incubation in aqueous medium and, therefore, contained more free chains in their eluates which could interact with the released HRP. The release of biomolecules in their active form is a key issue when a new drug delivery system is designed. In this regard, the literature has already reported many approaches aiming at increasing HRP half-life. For instance, Al-Azzam and colleagues covalently grafted poly(ethylene glycol) moieties to HRP, 30 while other groups successfully encapsulated the enzyme into micro- or nano-particles (e.g., acetylated dextran, silica) with no detrimental effects on its functionality. ${ }^{31-33}$ Differently from micro- and nanocarriers, hydrogels do not show dimensional restrictions on the maximum payload they can encapsulate. Hence, in principle, the amount of payload encapsulated could be increased to a certain extent (based on the effects of loading procedure on the overall properties of the systems and biomolecule solubility) so that the released molecule in its active form exerts the desired therapeutic effect.

\section{Conclusions}

In this study, Poloxamer ${ }^{\circledR}$ P407, an aliphatic diisocyanate and an amino acidderived diamine were employed to synthesize an amphiphilic poly(ether urethane), according to a well-established protocol.19,24 Aqueous solutions based on this polymer were then studied as potential thermo-sensitive sol-gel systems suitable for drug delivery applications. Three compositions $(8,15,18 \% \mathrm{w} / \mathrm{v})$ were selected based on tube inverting tests results, showing solto-gel transition around physiological temperatures $\left(30-37^{\circ} \mathrm{C}\right)$ and complete gelation within few minutes at body temperature. Rheological characterization and stability to dissolution test highlighted the possibility to finely tune the properties of the resulting gels by changing PEU content in the starting aqueous solutions: systems with an $8 \%$ w/v PEU concentration showed poor mechanical properties and fast dissolution in aqueous media, while gels at a 15 and $18 \% \mathrm{w} / \mathrm{v}$ PEU concentration showed good PBS absorption and stability to dissolution up to 14 days. The ability of the developed gels to encapsulate and release drugs and biomolecules was assessed using two model proteins, bovine serum albumin and horseradish peroxidase. Both BSA and HRP were effectively encapsulated in mild conditions with no significant effects on LCGT values, rheological properties and stability in aqueous medium of the resulting systems. The release kinetics was similar for both the proteins, with no statistical differences; release from KHP407_8\% w/v gels was completed after 3 days of incubation, in agreement with their short residence time in aqueous media, while it was more sustained from gels at higher PEU concentration, reaching a complete release after 10-14 days. Activity assay on the released HRP revealed that about $30-40 \%$ of the enzyme was released in an active form, in accordance with other studies, 27,28 with a more pronounced inactivation found for less stable gels. Hence, new injectable thermo-sensitive sol-to-gel systems with highly tunable mechanical properties, residence time in aqueous environment and payload release rate have been successfully developed as promising platform for tissue engineering/regenerative medicine applications. The developed sol-gel systems could thus realistically answer to the clinical need on new easily injectable drug delivery systems releasing therapeutic proteins (e.g., 17 antibodies, hormones, enzymes, growth factors -GFs-) in a sustained, controlled and active form in loco. For instance, the designed sol-gel systems could find widespread application in the field of wound healing upon encapsulation of platelet lysate ${ }^{34}$ or selected GFs, ${ }^{35}$ as well as in the treatment of myocardial infarction upon loading of specific GFs, such as basic fibroblast growth factor (bFGF) 36,37 and insulin-like growth factor-1 (IGF-1). ${ }^{38}$

\section{References}

1. Vashist A, Ahmad S. Hydrogels: smart materials for drug delivery. Orient J Chem 2013;29:861-70.

2. Hoffman AS. Hydrogels for biomedical applications. Adv Drug Deliv Rev 2002;54:3-12.

3. Peppas NA, Hilt JZ, Khademhosseini A, Langer R. Hydrogels in biology and medicine: from molecular principles to bionanotechnology. Adv Mater 2006;18:1345-60.

4. Ahmed EM. Hydrogel: Preparation, characterization, and applications: A review. J Adv Res 2015;6:105-21.

5. Hoare TR, Kohane DS. Hydrogels in drug delivery: Progress and challenges. Polymer 2008;49:1993-2007.

6. Wenzel JGW, Balaji KSS, Koushik K, et al. Pluronic F127 gel formulations of deslorelin and $\mathrm{GnRH}$ reduce drug degradation and sustain drug release and effect in cattle. J Control Release 2002;85:51-9.

7. Veyries M, Couarraze G, Geiger S, et al. Controlled release of vancomycin from Poloxamer 407 gels. Int J Pharm 1999;192:183-93.

8. Yoo H-J, Kim H-D. Synthesis and properties of waterborne polyurethane hydrogels for wound healing dressings. J Biomed Mater Res Part B Appl Biomater 2008;85B:326-33.

9. Hatefi A, Amsden B. Biodegradable injectable in situ forming drug delivery systems. J Control Release 2002;80:928 .

10. Boffito M, Sirianni P, Di Rienzo AM, Chiono V. Thermosensitive block copolymer hydrogels based on poly(Ecaprolactone) and polyethylene glycol for biomedical applications: State of the art and future perspectives. J Biomed Mater Res - Part A 2015;103:1276-90.

11. Yang Y, Wang J, Zhang X, et al. A novel mixed micelle gel with thermo-sensitive property for the local delivery of docetaxel. J Control Release 2009; 135:17582

12. Brunet-Maheu J-M, Fernandes JC, De Lacerda CA, et al. Pluronic F-127 as a cell carrier for bone tissue engineering. J Biomater Appl 2009;24:275-87.

13. Volkmer E, Leicht U, Moritz M, et al. Poloxamer-based hydrogels hardening at body core temperature as carriers for cell based therapies: in vitro and in vivo analysis. J Mater Sci Mater Med 2013;24:2223-34.

14. Cohn D, Sosnik A, Levy A. Improved reverse thermo-responsive polymeric systems. Biomaterials 2003;24:370714.

15. Loh XJ, Gan HX, Wang H, et al. New thermogelling poly(ether carbonate urethane)s based on pluronics F127 and poly(polytetrahydrofuran carbonate). J Appl Polym Sci 2014;131:39924.

16. Ma G, Miao B, Song C. Thermosensitive PCL-PEG-PCL hydrogels: Synthesis, characterization, and delivery of proteins. J Appl Polym Sci 2010;116:1985-93.

17. Ibaraki N, Lin LR, Reddy VN. Effects of growth factors on proliferation and differentiation in human lens epithelial cells in early subculture. Investig Ophthalmol Vis Sci 1995;36:2304-12. 
18. Jia Y-Y, Zhou J-Y, Chang Y, et al. Effect of optimized concentrations of basic fibroblast growth factor and epidermal growth factor on proliferation of fibroblasts and expression of collagen: related to pelvic floor tissue regeneration. Chin Med J (Engl) 2018;131:2089-96.

19. Boffito M, Gioffredi E, Chiono V, et al. Novel polyurethane-based thermosensitive hydrogels as drug release and tissue engineering platforms: Design and in vitro characterization. Polym Int 2016;65:756-69.

20. Alexandridis P, Holzwarth JF, Hatton TA. Micellization of poly(ethylene oxide)-poly(propylene oxide)-poly(ethylene oxide) triblock copolymers in aqueous solutions: thermodynamics of copolymer association. Macromolecules 1994;27:2414-25.

21. Bohorquez M, Koch C, Trygstad T, Pandit N. A study of the temperaturedependent micellization of pluronic F127. J Colloid Interface Sci 1999;216:34-40.

22. Gioffredi E, Boffito M, Calzone S, et al. Pluronic F127 hydrogel characterization and biofabrication in cellularized constructs for tissue engineering applications. Procedia CIRP 2016;49:12532.

23. Cohn D, Sosnik A, Levy A. Improved reverse thermo-responsive polymeric systems. Biomaterials 2003;24:370714.

24. Pontremoli C, Boffito M, Fiorilli S, et al. Hybrid injectable platforms for the in situ delivery of therapeutic ions from mesoporous glasses. Chem Eng J
2018;340:103-13.

25. Tan S, Gu D, Liu H, Liu Q. Detection of a single enzyme molecule based on a solid-state nanopore sensor. Nanotechnology 2016;27:155502.

26. Lorber B, Fischer F, Bailly M, et al. Protein analysis by dynamic light scattering: Methods and techniques for students. Biochem Mol Biol Educ 2012;40:372-82.

27. Diniz Oliveira HF, Weiner AA, Majumder A, Shastri VP. Non-covalent surface engineering of an alloplastic polymeric bone graft material for controlled protein release. J Control Release 2008;126:237-45.

28. Weiner AA, Bock EA, Gipson ME, Shastri VP. Photocrosslinked anhydride systems for long-term protein release. Biomaterials 2008;29:2400-7.

29. Guo J, Zhong R, Li W, et al. Interaction study on bovine serum albumin physically binding to silver nanoparticles: Evolution from discrete conjugates to protein coronas. Appl Surf Sci 2015;359:82-8.

30. Al-Azzam W, Pastrana EA, King B, et al. Effect of the covalent modification of horseradish peroxidase with poly(ethylene glycol) on the activity and stability upon encapsulation in polyester microspheres. J Pharm Sci 2005;94:1808-19.

31. Kanthamneni N, Sharma S, Meenach $\mathrm{SA}$, et al. Enhanced stability of horseradish peroxidase encapsulated in acetalated dextran microparticles stored outside cold chain conditions. Int J Pharm 2012;431:101-10.
32. Chang F-P, Hung Y, Chang J-H, et al. Enzyme encapsulated hollow silica nanospheres for intracellular biocatalysis. ACS Appl Mater Interfaces 2014;6:6883-90.

33. Chiu Y-R, Ho W-J, Chao J-S, Yuan C-J. Enzyme-encapsulated silica nanoparticle for cancer chemotherapy. J Nanoparticle Res 2012;14:829.

34. Barsotti MC, Losi P, Briganti E, et al. Effect of platelet lysate on human cells involved in different phases of wound healing. PLoS One 2013;8:e84753.

35. Park JW, Hwang SR, Yoon IS. Advanced growth factor delivery systems in wound management and skin regeneration. Molecules 2017;22:1259.

36. Zhu H, Li X, Yuan $M$, et al. Intramyocardial delivery of bFGF with a biodegradable and thermosensitive hydrogel improves angiogenesis and cardio-protection in infarcted myocardium. Exp Ther Med 2017;14: 3609-15.

37. Li Z, Masumoto H, Jo J, et al. Sustained release of basic fibroblast growth factor using gelatin hydrogel improved left ventricular function through the alteration of collagen subtype in a rat chronic myocardial infarction model. Gen Thorac Cardiovasc Surg 2018;66:6417.

38. Li Z, Xu Y, Li H, Guan J. Immobilization of insulin-like growth factor-1 onto thermosensitive hydrogels to enhance cardiac progenitor cell survival and differentiation under ischemic conditions. Sci China Chem 2014;57: 568-78. 